OPEN ACCESS

Edited by:

Hansen Wang

University of Toronto, Canada

Reviewed by:

Sharon Marie Donovan,

University of Illinois at

Urbana-Champaign, USA

Josef $\mathrm{Neu}$,

University of Florida, USA

Aletta D. Kraneveld,

Utrecht University, Netherlands

*Correspondence:

Ying Han

hanying1568@126.com

Received: 23 November 2016 Accepted: 10 April 2017

Published: 28 April 2017

Citation:

$L i Q$, Han Y, Dy $A B C$ and Hagerman RJ (2017) The Gut Microbiota and

Autism Spectrum Disorders.

Front. Cell. Neurosci. 11:120.

doi: 10.3389/fncel.2017.00120

\section{The Gut Microbiota and Autism Spectrum Disorders}

\author{
Qinrui Li ${ }^{1}$, Ying Han ${ }^{1 *}$, Angel Belle C. Dy ${ }^{2}$ and Randi J. Hagerman ${ }^{3,4}$ \\ ${ }^{1}$ Department of Pediatrics, Peking University First Hospital, Beijing, China, ${ }^{2}$ School of Medicine and Public Health, Ateneo de \\ Manila University, Quezon City, Philippines, ${ }^{3}$ MIND Institute, University of California Davis Medical Center, Sacramento, CA, \\ USA, ${ }^{4}$ Department of Pediatrics, University of California Davis Medical Center, Sacramento, CA, USA
}

Gastrointestinal (Gl) symptoms are a common comorbidity in patients with autism spectrum disorder (ASD), but the underlying mechanisms are unknown. Many studies have shown alterations in the composition of the fecal flora and metabolic products of the gut microbiome in patients with ASD. The gut microbiota influences brain development and behaviors through the neuroendocrine, neuroimmune and autonomic nervous systems. In addition, an abnormal gut microbiota is associated with several diseases, such as inflammatory bowel disease (IBD), ASD and mood disorders. Here, we review the bidirectional interactions between the central nervous system and the gastrointestinal tract (brain-gut axis) and the role of the gut microbiota in the central nervous system (CNS) and ASD. Microbiome-mediated therapies might be a safe and effective treatment for ASD.

Keywords: autism spectrum disorder (ASD), gut microbiota, brain-gut axis, probiotics, fecal microbiota transplantation (FMT)

Autism spectrum disorder (ASD) constitutes a group of brain developmental disorders, and it is defined by stereotyped behavior and deficits in communication and social interaction. ASD has a significant influence on the development of children and on society. In 2012, the estimated prevalence of ASD was 14.6 per 1,000 children aged 8 years, and the prevalence was significantly higher in boys $(23.6$ per 1,000$)$ than that in girls $(5.3$ per 1,000) (Christensen et al., 2016). The cost of caring for a child with ASD but without an intellectual disability is $£ 0.92$ million in the United Kingdom and \$1.4 million in the United States. The main costs associated with the care of children with ASD are special education services and a loss of parental productivity (Buescher et al., 2014). Therefore, the economic effects of ASD have prompted researchers to search for effective interventions. However, identifying the exact etiology and pathology of ASD is difficult, and available effective therapies are limited (Rossignol and Frye, 2012). Previous studies have focused on genetic causes, dysregulation of the immune system, inflammation, exposure to environmental toxicants, and the gut microbiota (Fakhoury, 2015). The heritability of ASD and autistic disorder was approximately 50\% among Swedish children, suggesting that both genetic and environmental factors play important roles in the development of ASD (Hallmayer et al., 2011; Sandin et al., 2014). Accumulating evidence demonstrates that gastrointestinal (GI) symptoms, such as abdominal pain, gaseousness, diarrhea, constipation and flatulence, are a common comorbidity in patients with ASD (Chaidez et al., 2014). A study by Gorrindo et al. identified constipation as the most common symptom (85\%) in children with ASD according to parental reports and evaluations by pediatric gastroenterologists (Gorrindo et al., 2012). The prevalence of GI symptoms ranges from 23 to $70 \%$ in children with ASD (Chaidez et al., 2014). Furthermore, the observed GI symptoms are 
associated with the severity of ASD (Adams et al., 2011; Gorrindo et al., 2012). Although these studies did not show a cause-effect relationship between GI symptoms and ASD, the findings suggest that the gut plays an important role in the etiology of ASD. The gut consists of millions of microbiota, and we hypothesize that the microbiota and its metabolites might be involved in the pathophysiology of ASD. Several articles have reviewed the influence of the gut microbiota on the animal central nervous system (CNS) and suggested the existence of a microbiota gut-brain axis (Bienenstock et al., 2015; Mayer et al., 2015). The microbiota-gut-brain axis is likely the method of communication between the brain and the gut microbiota. This article reviews the role of the gut microbiota in the pathology of ASD. Strategies that modulate the gut microbiota might constitute a potential therapy for patients with ASD.

\section{GUT MICROBIOTA}

The human gut consists of approximately $1 \mathrm{~kg}$ of bacteria, and the number of bacterial genes are in the gut is approximately about 9.9 million. The ratio of host DNA vs. microbiome DNA is $1: 10$. ( $\mathrm{Li}$ et al., 2014). Our knowledge of the microbiome has excessively expanded over the last few years. For example, researchers previously believed that the in utero environment was sterile (Jimenéz et al., 2008; Martin et al., 2016). However, recent work has shown that the infant gut is colonized by the microbiome of the maternal vagina, anus and skin during delivery and by the environmental bacteria to which the neonate is exposed during the postpartum period (Dominguez-Bello et al., 2010; Bokulich et al., 2016; Yassour et al., 2016). As demonstrated in recent studies, the placenta and the amniotic fluid are not sterile (DiGiulio et al., 2008; Aagaard et al., 2014). In addition, the microbiome in the first meconium of mice is not sterile, indicating that the microbiome colonizes the infant gut prior to parturition (Jimenéz et al., 2008). Maternal factors, such as maternal diet and delivery mode, and postnatal factors, including antibiotics, breast-feeding, diet and host genetics, structure the neonatal microbiome in humans and animal models (Tamburini et al., 2016). Many studies have shown that a maternal highfat diet during pregnancy decreases the level of Bacteroides in human neonates and diminishes the abundance of nonpathogenic Campylobacter in primates (Ma et al., 2014; Chu et al., 2016). Furthermore, maternal obesity during pregnancy and gestational diabetes alter the gut microbiota and might be associated with ASD in humans (Connolly et al., 2016). As shown by Buffington et al., a maternal high-fat diet induces dysbiosis and autism-like phenotypes in mice, and Lactobacillus reuteri restores these alternations (Buffington et al., 2016). The birth mode and antibiotics also shape the gut microbiota (Bokulich et al., 2016). The gut microbiota of infants who were delivered vaginally resembles their mother's vaginal microbiota, which is dominated by Lactobacillus, Prevotella, or Sneathia spp., and the gut microbiota of babies who were born by Cesarean section is similar to their mother's skin microbiota, which is dominated by Staphylococcus, Corynebacterium, and Propionibacterium spp.
(Dominguez-Bello et al., 2010). As shown by Yassour et al., the composition of the microbiota of children who were treated with antibiotics during the first 3 years of life is less diverse in terms of both bacterial species and strains (Yassour et al., 2016). A population-based cohort study revealed the use of various antibiotics during pregnancy as a potential risk factor for ASD/infantile autism (Atladóttir et al., 2012). The early feeding pattern also influences the gut microbiota of infants and is associated with ASD. Formula-fed infants present an increased species richness accompanied by an overrepresentation of Clostridium difficile compared with breast-fed infants (Azad et al., 2013). Breast-feeding for more than 6 months is associated with a lower risk of developing ASD (Schultz et al., 2006). Penn et al. studied infants with an older sibling diagnosed with ASD in the San Diego area and found that breast-feeding might protect the infants against GI symptoms (Penn et al., 2016). As an individual's diet diversifies with increasing age, the gut microbiota gradually stabilizes (Koenig et al., 2011; Yatsunenko et al., 2012; Tamburini et al., 2016). A diet with lean ground beef increases the diversity of the gut microbiota and improves both working and reference memory in mice compared with a standard rodent chow diet, suggesting a correlation between diet-induced shifts in the gut microbiota and animal behaviors (Li et al., 2009a). Environmental exposure also affects the microbiota of humans. Furthermore, dysbiosis of the gut microbiota is associated with several disorders in children, such as abnormal behaviors, Crohn's disease, obesity and inflammatory bowel disease (IBD) (Ajslev et al., 2011; Cryan and Dinan, 2012; Jostins et al., 2012). In summary, the gut microbiota plays important roles in human physiology and pathology.

\section{RELATIONSHIP BETWEEN ASD AND GUT MICROBIOTA}

Gastrointestinal (GI) symptoms are prominent in ASD individuals. Wang et al., found more GI syndromes, including constipation (20\%) and diarrhea (19\%), in children with ASD than in their unaffected siblings (42 vs. 23\%, respectively) (Wang et al., 2011). Two meta-analyses showed similar results in children with ASD (Coury et al., 2012; McElhanon et al., 2014). Patients with ASD who present GI symptoms might display significant behavioral manifestations, such as anxiety, self-injury and aggression (Buie et al., 2010). Accumulating evidence demonstrates that the gut microbiota is directly or indirectly associated with ASD symptoms, in part by influencing the immune system and metabolism (De Angelis et al., 2015; Mead and Ashwood, 2015). A higher percentage of abnormal intestinal permeability was observed in $36.7 \%$ of patients with ASD and their relatives $(21.2 \%)$ compared with control children $(4.8 \%)$ (de Magistris et al., 2010). An increased intestinal permeability results in a higher antigenic load from the gastrointestinal tract. Lymphocytes and ASD-associated cytokines, such as interleukin-1 $\beta$ (IL-1 $\beta$ ), IL-6, interferon- $\gamma$ (IFN- $\gamma$ ), and tumor necrosis factor-a (TNF- $\alpha$ ), are present in the circulation and cross the blood-brain barrier (BBB). Subsequently, IL-1 $\beta$ and 
TNF- $\alpha$ bind to brain endothelial cells and induce immune responses in the brain (Li et al., 2009b; Ashwood et al., 2011; de Theije et al., 2011). Alterations in the composition of the gut microbiota and their metabolic products are commonly observed in patients with ASD and in animal models of ASD (de Magistris et al., 2010; Borre et al., 2014; Kushak et al., 2016). Hsiao et al. observed gastrointestinal barrier defects and microbiota alterations in a mouse model displaying features of ASD. They found that bacteria belonging to Porphyromonadaceae, Prevotellaceae, unclassified Bacteroidales, and Lachnospiraceae were more abundant in offspring of mothers with maternal immune activation (MIA) than in control offspring, whereas Ruminococcaceae, Erysipelotrichaceae, and Alcaligenaceae were more abundant in the latter (Hsiao et al., 2013). As shown in mice, the anti-epileptic drug valproic acid (VPA), when used by the mother during pregnancy, induces autistic-like social behaviors in the offspring accompanied by alterations in Bacteroidetes and Firmicutes (de Theije et al., 2014b). Compared with the gut microbiota of children without ASD, the gut microbiota of children with ASD is less diverse and exhibits lower levels of Bifidobacterium and Firmicutes and higher levels of Lactobacillus, Clostridium, Bacteroidetes, Desulfovibrio, Caloramator and Sarcina (Finegold et al., 2002, 2010; Adams et al., 2011; Finegold, 2011; De Angelis et al., 2013). Children with autism who present GI symptoms have lower abundances of the genera Prevotella, Coprococcus, and unclassified Veillonellaceae than that found in GI symptom-free neurotypical children (Kang et al., 2013). Fecal samples from children with ASD also have higher levels of the Clostridium histolyticum group (Clostridium clusters II and I) compared with samples from unrelated healthy children (Parracho et al., 2005). The non-autistic sibling group presents an intermediate level of Clostridium histolyticum that does not significantly differ from the ASD group. Clostridium can produce neurotoxins and might exert systemic effects (Parracho et al., 2005). The reduction of Clostridium yields significant improvements in children with ASD (Sandler et al., 2000). Additionally, children with ASD present alterations in their levels of Bifidobacterium, Prevotella, and Sutterella (Wang et al., 2013). Ruminococcus torques has been associated with functional GI disorder (Joossens et al., 2011). Infants who were delivered by Cesarean section (CS) are at higher risk of developing ASD (odds ratio of 1.23) than infants delivered vaginally (Curran et al., 2015). Children with ASD have a history of using significantly more antibiotics (Niehus and Lord, 2006; Shultz et al., 2008; Atladóttir et al., 2010, 2012). Thus, early life events that can alter the composition of the microbial community, such as delivery mode and antibiotic exposure, are risk factors for ASD. However, some studies have not found an association between ASD and the gut microbiota. A study of 59 ASD individuals and 44 normal siblings via targeted qPCR found no significant difference in Sutterella, Prevotella or total Bacteroidetes composition between them (Son et al., 2015).

Although many studies have demonstrated alternations to the bacterial gut microbiota in ASD patients, fewer studies have evaluated the relationships between gut fungi and ASD. The yeast in gut (particularly Candida. albicans) result in absorbing carbohydrates and minerals fewer and releasing higher toxins.
Kantarcioglu et al. isolated 338 yeast strains from 415 stool samples of ASD individuals. Among the yeast strain, $81.4 \%$ were Candida (particularly Candida. albicans). Lower yeast isolated rate $(19.6 \%)$ were identified in non-autistic healthy volunteers. Candida. krusei and Candida. glabrata were not found in healthy children (De Angelis et al., 2013; Kantarcioglu et al., 2016). Strati et al., found a significant increase in the Firmicutes/Bacteroidetes ratio in autistic subjects relative to normal subjects. They also found that Candida was two times more abundant in autistic individuals than in normal individuals (Strati et al., 2017). The proliferation of Candida can be inhibited by IL-17, IL-22, which modulated by some species of Lactobacillus through tryptophanderived aryl hydrocarbon receptor ligands (Zelante et al., 2013). Candida can releases ammonia and toxins that can induce autistic behaviors (Burrus, 2012; Iovene et al., 2017). The alterations of the bacterial microbiota in ASD individuals result in the expansion of Candida, which would worsen the dysbiosis and induce the abnormal behaviors. In summary, the role of gut fungal in ASD still need more large samples studies.

\section{POTENTIAL RELATIONSHIPS BETWEEN THE MICROBIOTA AND ASD (THE GUT-BRAIN AXIS)}

The gut-brain axis is regarded as a pathway of communication between the gut and the brain, and it is a bidirectional communication system. An increasing body of evidence shows that the gut-brain axis participates in the pathogenesis of ASD. The gut microbiota influences brain function through the neuroendocrine, neuroimmune and autonomic nervous systems and via microbiotic toxin production (Grenham et al., 2011; Mayer, 2011; Figure 1). The mucosa of the gastrointestinal tract contains millions of neurons, which constitute the enteric nervous system (ENS) and regulate gastrointestinal functions. Therefore, the gut is considered as a "second brain." Figure 1 outlines the potential relationships between the gut microbiota and ASD.

A fundamental factor underlying the relationships between ASD and the gut is the increased permeability of the intestinal tract of ASD individuals, referred to as a "leaky gut" (Quigley, 2016). Previous studies have demonstrated that ASD animals present defects in the GI barrier, resulting in the entry of the toxins and bacterial products into the bloodstream, which influence brain function (Onore et al., 2012; Hsiao et al., 2013). For example, lipopolysaccharide (LPS), components of the cell wall of gram-negative bacteria, is increased in the serum of ASD compared with healthy individuals and is associated with impaired social behavioral scores (Emanuele et al., 2010). Fiorentino et al., found that the integrity of both the gut barrier and the BBB were impaired in ASD individuals, as evidenced by increased levels of claudin (CLDN)-5, CLDN12, CLDN-3, and MMP-9 in the ASD brain and decreased levels of intestinal tight junction components (CLDN-1, OCLN, TRIC) in ASD individuals compared with controls. (Fiorentino et al., 2016). Intestinal permeability, measured by the lactulose: mannitol test, has been shown to be increased in autistic 


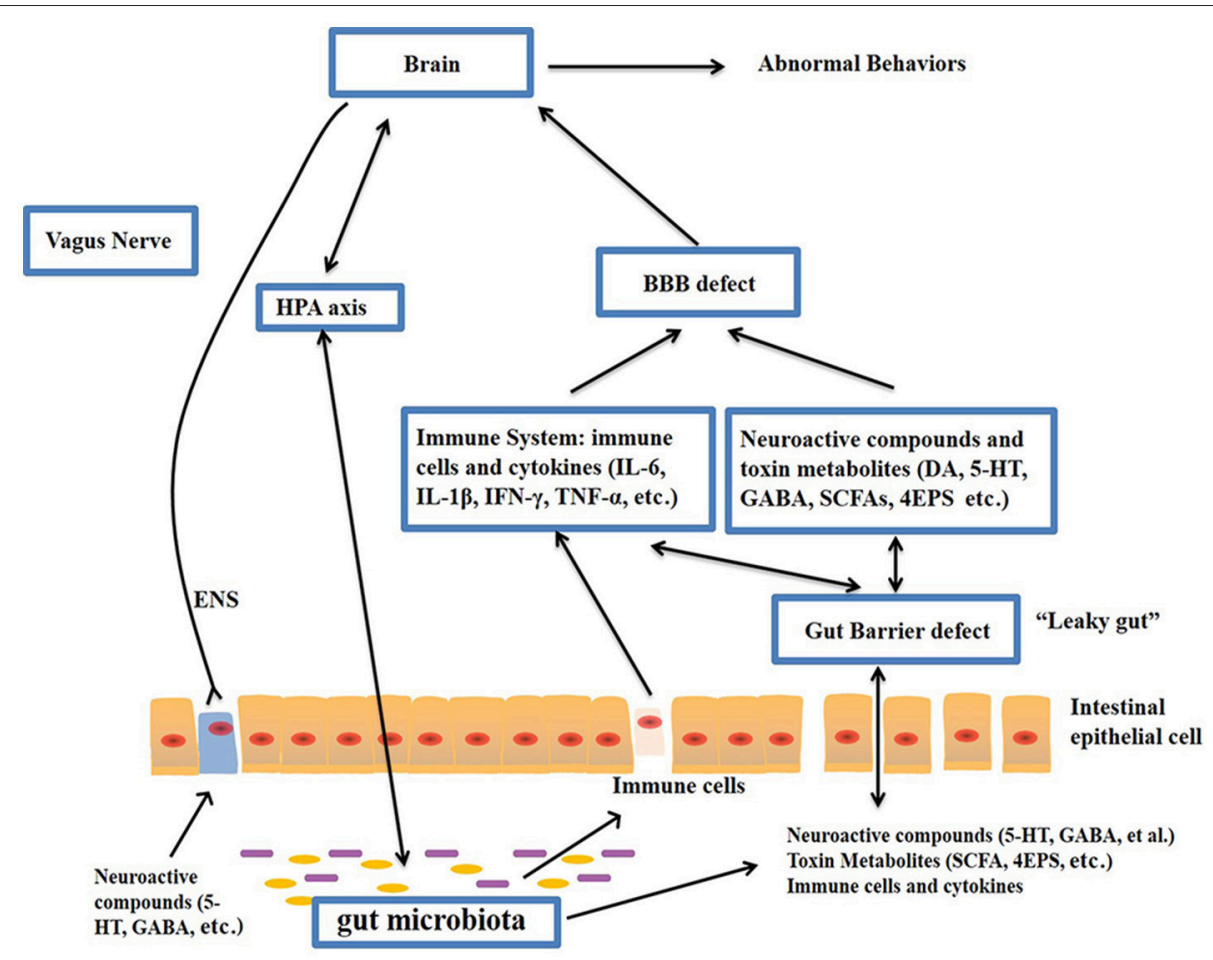

FIGURE 1 | Potential relationships between the microbiota and ASD (the gut-brain axis). The production of metabolites, such as SCFAs and toxin metabolites, by certain microbiota (e.g., Lactobacillus) can cross the "leaky gut" to affect brain function. Some microbiota can produce neuroactive compounds (e.g., 5-HT and GABA) that cross the "leaky gut" and influence brain function and induce abnormal behaviors. These neuroactive compounds can directly influence the HPA axis and increase circulating levels of cortisol. Metabolites, certain microbiota and neuroactive compounds can activate enteric neurons and affect brain function through the vagus nerve. Some microbiota and metabolites can activate gut immune cells, which can release cytokines into circulation. 4-EPS, 4-ethylphenyl sulfate; 5-HT, serotonin; HPA, hypothalamic-pituitary-adrenal; SCFAs, short-chain fatty acids; BBB, blood-brain barrier; 5-HT, 5-hydroxytryptamine; ENS, enteric nervous system; GABA, $\gamma$-aminobutyric acid; DA, dopamine.

children compared with healthy controls (de Magistris et al., 2010). Furthermore, germ-free (GF) mice display increased BBB permeability. Bacterial products (e.g., acetate and propionate) can enhance the integrity of the BBB (Braniste et al., 2014).

\section{Gut Microbiota-Mediated Metabolites}

Gut microbiota-mediated metabolites, such as short-chain fatty acids (SCFAs), phenol compounds, and free amino acids (FAA), affect ASD-like behaviors through the vagal pathways (Shimmura et al., 2011; Macfabe, 2012; Persico and Napolioni, 2013; Forsythe et al., 2014).

SCFAs, including acetic acid (AA), proprionic acid (PPA), butyrate, isobutyric acid, valeric acid and isovaleric acid, are principal products of the gut bacterial fermentation of nondigestible carbohydrates (Al-Lahham et al., 2010) and provide benefits to the host, including improvements in glucose and energy homeostasis and reductions in body weight and the risk of colon cancer (Mariadason et al., 2000; De Vadder et al., 2014; Chambers et al., 2015). According to several studies, SCFAs play a critical role in patients with ASD. A study by Wang et al., detected higher concentrations of total SCFAs and ammonia in fecal matter from children with autism compared with controls (Wang et al., 2012). PPA, a short-chain fatty acid that is mainly produced by Clostridia, Bacteroidetes, and
Desulfovibrio, can cross the $\mathrm{BBB}$ and induce ASD-like behaviors (MacFabe et al., 2007, 2011; Shultz et al., 2008; Ossenkopp et al., 2012). As shown by Thomas et al., the intracerebroventricular administration of high doses of PPA provokes some autistic-like behaviors in mice (Thomas et al., 2012), and the intraventricular administration of PPA to rats results in hyperactivity, repetitive behaviors and abnormal motor movements, similar to the behavioral and electrographic changes detected in humans with ASD (MacFabe et al., 2007). PPA leads to impaired social behavior in rats, likely by altering some neurotransmitters, such as dopamine and serotonin (Mitsui et al., 2005). Butyrate can modulate synthesis of the neurotransmitters dopamine, norepinephrine and epinephrine by altering expression of the tyrosine hydroxylase gene (DeCastro et al., 2005). Butyrate also inhibits histone deacetylases and possesses anti-inflammatory effects (Cleophas et al., 2016). Researchers have found lower serum levels of 4-ethylphenylsulfate (4EPS), indolepyruvate, glycolate, imidazole propionate and $\mathrm{N}$-acetylserine in a MIA model of ASD. Naïve wild-type mice treated with 4EPS potassium salt presents ASD-related behavior (Hsiao et al., 2013). FAA, derived from the hydrolysis of proteins and peptides, has also been found to be associated with ASD. De Angelis et al., found that the level of total FAA in fecal samples was higher in children with autism than that in heathy children. In addition, the levels 
of Asp, Ser, Glu, Gly, Ala, Val, Ile, Phe, His, Tpr, Lys, and Pro in fecal samples were higher in the children with autism (De Angelis et al., 2015). Glu, a neurotransmitters in the CNS, has been found to be associated with some neuropsychiatric disorders and ASD (Sheldon and Robinson, 2007; Shimmura et al., 2011). Noto et al., found that tryptophan, a neurotransmitter precursor, was increased in the urine of ASD patients. In addition, they found increased levels of tryptophan fragments in urine and increased tryptophan degradation, which are also found in depression and mental retardation (Noto et al., 2014). When compared with urine samples from control children, the urine samples from children with ASD contain higher levels of 2-(4hydroxyphenyl) propionate and taurocholenate sulfate and lower levels of 3-(3-hydroxyphenyl) propionate and 5-amino-valerate (Ming et al., 2012). 3-(3-hydroxyphenyl)-3-hydroxypropanoic acid, a phenylalanine metabolite of Clostridia spp. was shown to be increased in the urine of ASD patients and is associated with autistic behaviors in animals (Shaw, 2010).

\section{The Immune System Pathways}

The gut can also communicate with the brain through immunological pathways. Many studies have shown increased levels of pro-inflammatory cytokines, such as IL-1 $\beta$, IL-6, IL8 , and IL-12p40, in the plasma of ASD individuals (Ashwood et al., 2011). Immune responses to toxins produced by pathogenic microbiota and focal inflammation increase gut permeability. An impaired intestinal barrier is observed in response to infection or stress, which allows the translocation of the gut bacteria across the intestinal wall and into the mesenteric lymphoid tissue, where they activate the immune system through mucosal immune cells (Dicksved et al., 2012). The activated immune system releases inflammatory cytokines and activates the vagal system, which in turn regulates CNS activity (Yarandi et al., 2016). Konsman et al., found peripheral cytokines to induce behavioral depression through the vagus nerve (Konsman et al., 2000). Moreover, metabolic compounds, such as lipopolysaccharide (LPS) produced by gut microbiota, are absorbed into the blood through an impaired gut wall and activate Toll-like receptors in the ENS and CNS (Abreu, 2010). An IgEmediated allergic immune response in the intestine increases the 5-hydroxytryptamine (5-HT) levels and decreases the 5hydroxyindoleacetic acid (5-HIAA) levels in the intestine. It also reduces social communication and increases repetitive behavior. It mice, these effects are accompanied by a downregulation of dopaminergic activity in the prefrontal cortex and activation of the neuroendocrine system in mice (de Theije et al., 2014b).

\section{Neuroactive Compound Pathways}

The pathway via which the microbiota communicate with the brain can also involve neurotransmitters. The gut microbiota produces neuroactive compounds such as dopamine (DA), 5HT, $\gamma$-aminobutyric acid (GABA) and histamine, which activate or inhibit central neurons through the vagus nerve (Eisenstein, 2016; Spiller and Major, 2016). Compared with specificpathogen-free (SPF) mice with a normal gut microbiota, GF mice exhibit a significant elevation of monoamine neurotransmission (of compounds such as noradrenaline, DA and 5-HT), decreased levels of nerve growth factor-inducible clone A (NGFIA) and brain-derived neurotrophic factor (BDNF), increased corticosterone levels, and increased anxiety-like behaviors (Diaz Heijtz et al., 2011; Neufeld et al., 2011; Clarke et al., 2013). Antibiotic-induced depletion of the gut microbiota in mice impairs learning and increases depression-like behaviors. Furthermore, the levels of CNS neurotransmitters (e.g., 5HT, 5-hydroxyindoleacetic acid, noradrenaline, DA and the metabolite homovanillic acid) as well as the mRNA levels of the glucocorticoid receptor and corticotrophin-releasing hormone receptor 1 have been shown to be altered (Hoban et al., 2016). The gut microbiota also affects mammalian brain development and subsequent adult behavior. For instance, GF mice display lower expression of postsynaptic density protein 95 (PSD95) and synaptophysin in the striatum, increased monoamine neurotransmission and motor activity and reduced anxiety compared with SPF mice (Diamond et al., 2011; Diaz Heijtz et al., 2011). Blood serotonin (5-HT) was the first ASD biomarker identified and is present in approximately 30\% of individuals with ASD (Pare et al., 1960; Schain and Freedman, 1961; Hanley et al., 1977; Mulder et al., 2004). SERT 5-HT transporter (SERT) Ala56-knock-in mice, which display hyperserotonemia as a result of increased neuronal absorption of 5-HT, show abnormal social behaviors, nonstandard communication, and repetitive behaviors (Veenstra-VanderWeele et al., 2012). Serotonin, which is synthesized in the intestines and brain, is important for the regulation of mood and cognition (Cryan et al., 2000). Marler et al., found an association between whole-blood serotonin levels and GI symptoms in ASD individuals (Marler et al., 2016). Compared to the brains of offspring from the control mice, the brains of offspring from VPA-exposed mice present altered microbiota and lower levels of serotonin and ASD-like behavior (de Theije et al., 2014a).

\section{MODULATION OF THE GUT MICROBIOTA IS A POTENTIAL THERAPY FOR CHILDREN WITH ASD}

At present, there are no effective therapies for ASD. Parents often take their children to receive intervention that is tailored to their specific needs. It is urgent to look for risk-free and effective treatments. Accumulating evidences showed modulation of the gut microbiota is a potential therapy in children with ASD. Probiotics, prebiotics, fecal microbiota transplantation (FMT) and diet have getting considerable attention (Table 1). Probiotics may prevent intestinal inflammatory diseases by regulating intestinal tight junction protein expression and barrier function. The use of heat-killed probiotics may provide therapeutic benefit while minimizing adverse effects.

\section{Probiotics and Prebiotics}

Probiotics, such as the lactic acid-producing bacteria belonging to Lactococcin, Lactobacilli, Bifidobacteria and Saccharomycetes, are beneficial to the host when provided in adequate quantities. Many studies have shown that probiotics can prevent and treat a variety of diseases, such as obesity, depression, colorectal 


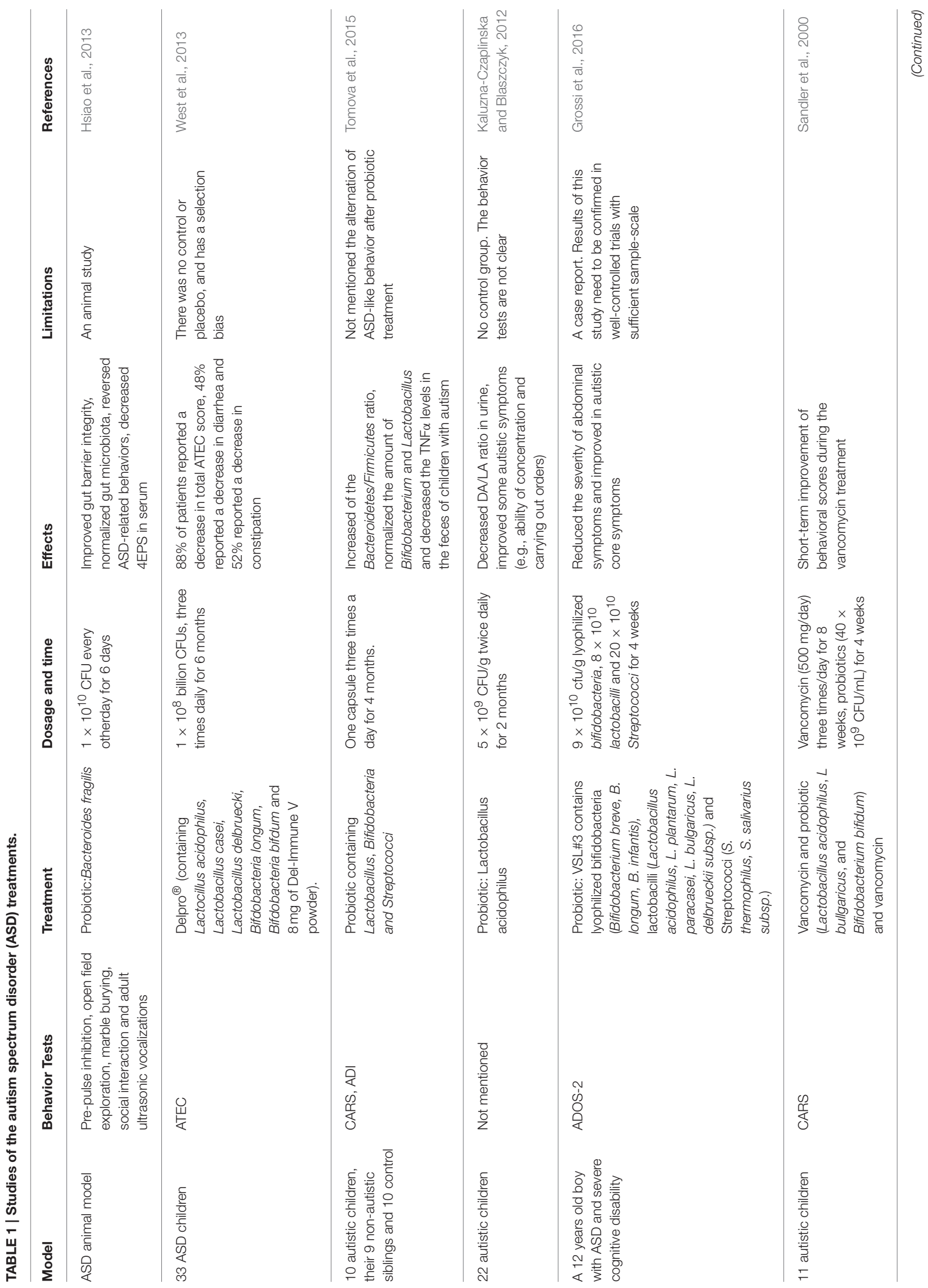




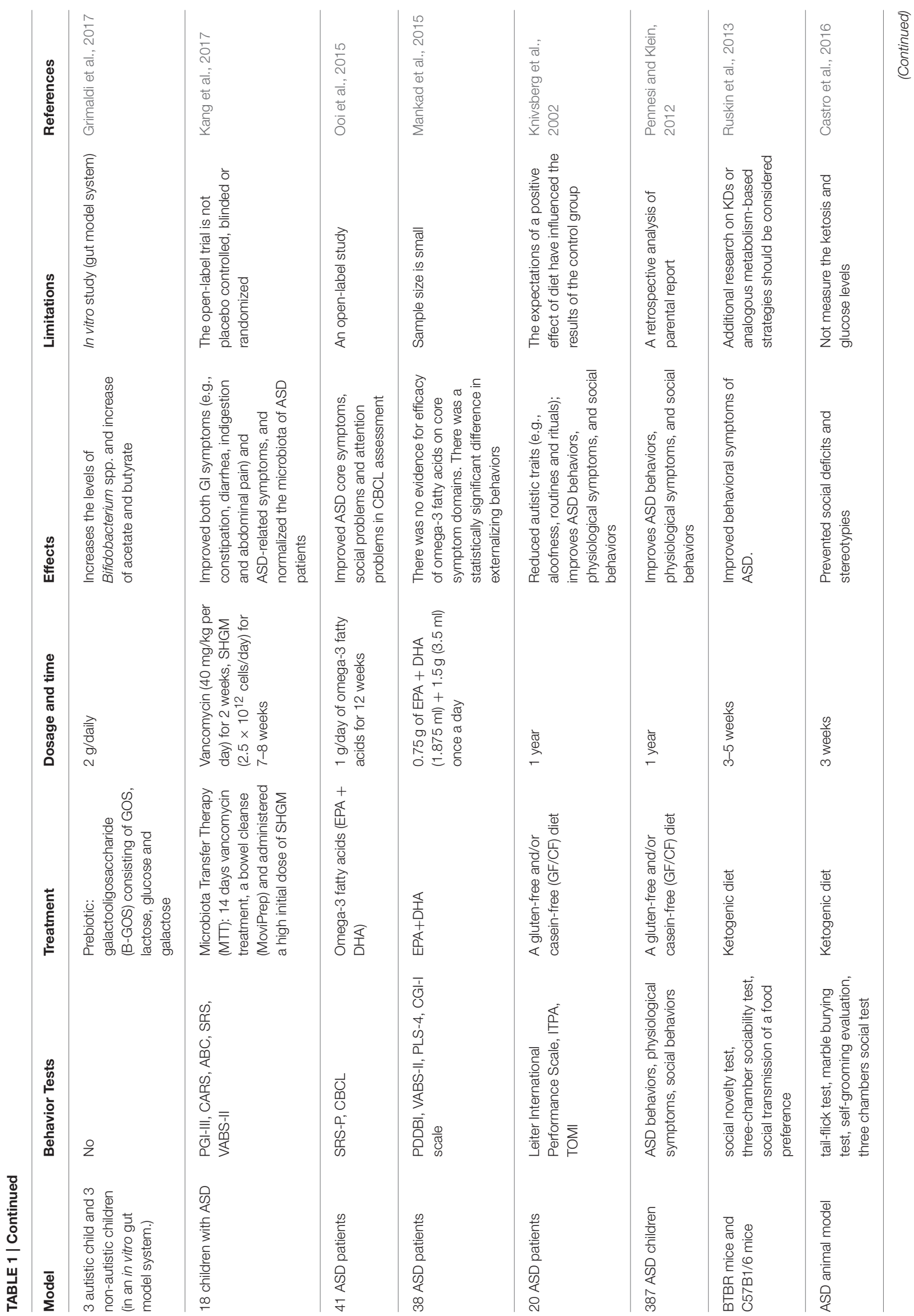




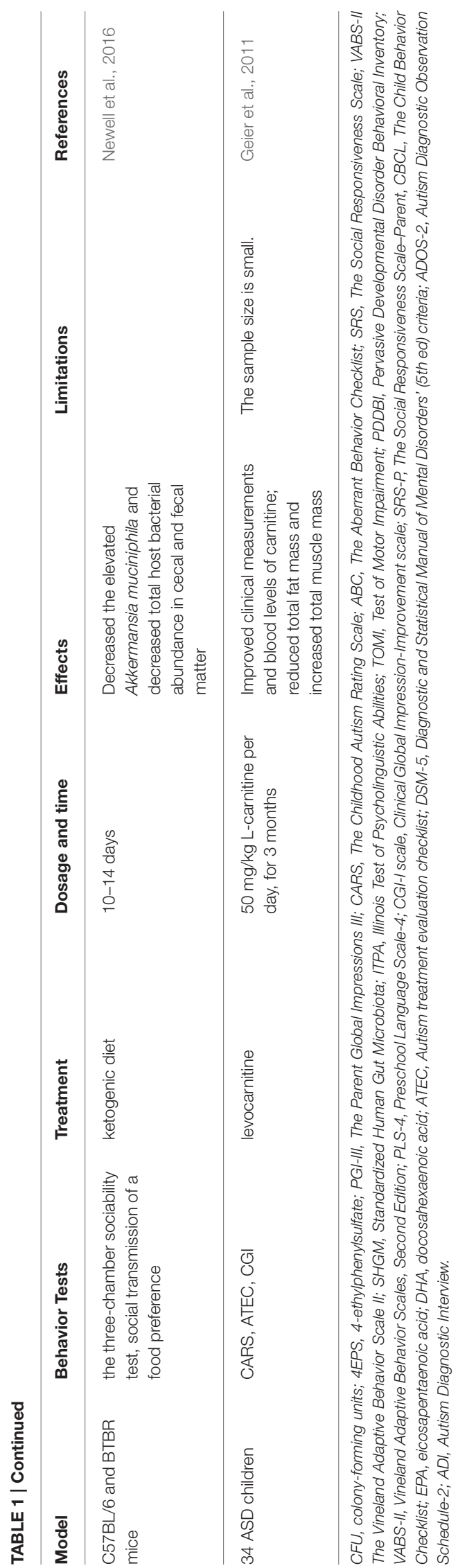

cancer and Crohn's disease, in animal models and humans (Verna and Lucak, 2010; Verma and Shukla, 2014; Sharma and Shukla, 2016; Valsecchi et al., 2016). In heathy women without gastrointestinal or psychiatric symptoms, the consumption of a fermented milk product containing Bifidobacterium animalis subsp lactis, Streptococcus thermophilus, Lactobacillus bulgaricus, and Lactococcus lactis subsp lactis results in robust alterations in activity in the brain regions that control the central processing of emotions and sensations, as observed by functional magnetic resonance imaging (Tillisch et al., 2013). Patients with irritable bowel syndrome (IBS) who were treated with $B$. infantis 35624 reported that alleviation of symptoms such as abdominal pain and distention and presented a normalized ratio of the immunomodulatory cytokines IL-10/IL-12 (O'Mahony et al., 2005; Whorwell et al., 2006). In a double-blind, placebocontrolled, randomized study, Lactobacillus helveticus R0052 and Bifidobacterium longum R0175 were administered to healthy women for 30 days, and then anxiety, depression, and 24$\mathrm{h}$ free cortisol levels in the urine were then assessed. The probiotics alleviated psychological distress and the 24-h urinary cortisol levels (Messaoudi et al., 2011). In another pilot clinical study, patients with chronic fatigue syndrome received 24 billion colony-forming units of Lactobacillus casei strain Shirota daily for 2 months, and a significant decrease in anxiety symptoms and a significant increase in Lactobacillus and Bifidobacteria were observed (Rao et al., 2009). Probiotic, such as Lactobacillus reuteri and Lactobacillus rhamnosus, have been shown to improve barrier function via altering the expression of tight junction proteins and decreased the bacterial translocation in animal models or in vitro (Ulluwishewa et al., 2011; Dicksved et al., 2012; Patel et al., 2012). Healthy human administered Lactobacillus plantarum strain WCFS1 in the duodenum enhanced the intestinal barrier by regulating human epithelial tight-junction proteins (Karczewski et al., 2010). Patel et al., found Lactobacillus rhamnosus GG (LGG) promoted intestinal barrier function maturation by inducing claudin 3 expression (Patel et al., 2012).

The probiotic/prebiotic can normalize the gut microbiota, enhance gut barrier and relieve the ASD-like behaviors in animal models or ASD patients. As shown by a study of Hsiao et al., treatment with Bacteroides fragilis reduced gut permeability, altered the composition of the gut microbiota and decreased ASD-like behaviors in a rodent model of ASD (Hsiao et al., 2013). West et al., found that the daily administration of the probiotic and immune modulator co-formulation Delpro ${ }^{\circledR}$ significantly improved GI and ASD symptoms (West et al., 2013). Supplementation with a probiotic containing Lactobacillus, Bifidobacteria and Streptococci normalizes the Bacteroidetes/Firmicutes ratio, and the amounts of Desulfovibrio spp. and Bifidobacterium spp. in the feces of children with ASD are similar to those found in samples from their nonautistic siblings or unrelated heathy controls. They also found the Autism Diagnostic Interview (ADI) restricted/repetitive behavior subscale score has associated with the amount of Desulfovibrio spp. (Tomova et al., 2015). However, the authors did not assess the alteration of ASD behavior after probiotic treatment. According to a cohort study, oral supplementation 
with Lactobacillus acidophilus twice daily for 2 months decreases the D-arabinitol levels in the urine of children with ASD and improves their ability to follow directions, as demonstrated through comparison with data collected before the treatment (Kaluzna-Czaplinska and Blaszczyk, 2012). A case study showed an ASD boy with severe cognitive disability was treated with VSL\#3 (a multi-strain mixture of 10 probiotics) for 4 weeks. The treatment relieved the GI symptoms and improved the autistic core symptoms (Grossi et al., 2016). In a recent clinical study, which is currently in progress, 100 preschoolers with ASD are being administered probiotics or a placebo for 6 months, and the results will provide new information regarding the clinical and neurophysiological effects of the probiotic treatment in children with ASD (Santocchi et al., 2016).

Probiotic treatments have a proven ability to normalize the microbiota and ameliorate gut symptoms; however, the available evidence for prebiotics is lacking. The term "prebiotics" refers to non-digestible oligosaccharides that induce the growth of beneficial bacteria (Rosenfeld, 2015). The prebiotic galactooligosaccharide (B-GOS) increases the levels of Bifidobacterium spp. in an in vitro gut model, as demonstrated through the analysis of fecal samples from children with ASD and controls (Grimaldi et al., 2017).

However, the positive roles of probiotics or prebiotics in humans are controversial. In summary, probiotic, and prebiotic treatment for ASD patients lack multicenter, large- sample, randomized controlled trial.

\section{Fecal Microbiota Transplantation (FMT)}

Fecal Microbiota Transplantation (FMT) is an intervention in which the fecal microbiota from a healthy individual is delivered to a patient with a dysbiotic gut microbiota. FMT dates back to fourth-century China, when a traditional Chinese medicine doctor described an oral human fecal suspension that effectively cured food poisoning and severe diarrhea (Zhang et al., 2012). It is highly efficacious in the treatment of recurrent Clostridium difficile infections (CDI) (Vrieze et al., 2013; Lessa et al., 2015). FMT has been applied to the treatment of IBD and IBS, based on the speculation that FMT can normalize the gut microbiota in patients with IBD and IBS, and improve constipation symptom (100\%) (Aroniadis and Brandt, 2013; Rossen et al., 2015). Thus, researchers are increasingly interested in using FMT to treat children with ASD. However, the safety of FMT should be considered. The potential adverse events of FMT include diarrhea, abdominal cramps, belching in the short term, mild abdominal discomfort/bloating, and transient low-grade fever (Kelly et al., 2015).

\section{Microbiota Transfer Therapy (MTT)}

Microbiota transfer therapy (MTT) is a modified FMT protocol comprising 14 days of antibiotic treatment followed by bowel cleansing and the administration of a high initial dose of standardized human gut microbiota (SHGM) for 7-8 weeks. An open-label clinical trial showed that MTT improved both
GI symptoms (e.g., constipation, diarrhea, indigestion and abdominal pain) and ASD-related symptoms and normalized the microbiota of ASD patients (Kang et al., 2017).

\section{Other Potential Therapies (e.g., Diet and Antibiotics)}

Children with ASD tolerate a narrower range of foods and exhibit more feeding problems than children without ASD (Schreck et al., 2004). Specifically, children with ASD refuse more foods and exhibit a more limited food repertoire than typically developing children (Bandini et al., 2010). Many parents complain that their children with ASD are selective eaters. Children with ASD reject foods for various reasons, including problems with the presentation of the food, the use of certain utensils, and the inclusion of different types of food on the same plate (Schreck and Williams, 2006). Compared with controls, children with ASD ingest fewer fruits, vegetables, and proteins and have a significantly lower daily intake of potassium, copper, folate, and calcium (Sharp et al., 2013; Malhi et al., 2017). Food intake influences the composition of the gut microbiota (Wu et al., 2011). Decreases in carbohydrate intake decrease the levels of Roseburia spp. and Eubacterium rectale (Duncan et al., 2007). Furthermore, diet-induced alterations in the location and composition of the gut microbiota influence the serum metabolite levels (Tremaroli and Bäckhed, 2012). According to an open-label trial, participants with ASD who are treated with omega-3 fatty acids for 12 weeks exhibit significant improvements in social behaviors (Ooi et al., 2015). However, high-dose supplementation with omega-3 fatty acids do not affect children with ASD, as demonstrated by a recent study (Mankad et al., 2015). A gluten-free and/or casein-free (GF/CF) diet improves ASD behaviors, physiological symptoms, and social behaviors (Knivsberg et al., 2002; Millward et al., 2004; Pennesi and Klein, 2012). The ketogenic diet is a highfat and low-carbohydrate diet and results in reductions in the total gut microbial counts, increased sociability, decreased repetitive behaviors, and improved social communication in an ASD animal model (Ruskin et al., 2013; Castro et al., 2016). Newell et al. found that the ketogenic diet reduces the total gut microbial abundance in cecal and fecal matter and normalizes the level of Akkermansia muciniphila in an ASD murine model (Newell et al., 2016). Children with regressive-onset autism who are treated with vancomycin, a broad-spectrum oral antibiotic, for a short period exhibit improvements in diarrhea and autistic behaviors (Sandler et al., 2000). Based on a prospective, double-blind, placebo-controlled trial, 3-month treatment with levocarnitine improves ASD symptoms in children with ASD (Geier et al., 2011). More clinical studies are needed to establish support for the use of dietary, antibiotic, and supplement treatments.

\section{CONCLUSION}

In this review, we summarize the information from multiple studies showing that an abnormal gut microbiota is related to ASD. First, we reviewed the relationship between the 
gut microbiota and the CNS. Second, we defined the role of the gut microbiota in ASD. Finally, we described some potential therapies for modulating the gut microbiota in patients with ASD. Many recent clinical studies have shown that treatments that regulate the gut microbiota result in improvements in ASD symptoms (Critchfield et al., 2011; Tomova et al., 2015). However, well-designed research studies with more participants are needed to provide more evidence that supports the effectiveness of these treatments.

\section{REFERENCES}

Aagaard, K., Ma, J., Antony, K. M., Ganu, R., Petrosino, J., and Versalovic, J. (2014). The placenta harbors a unique microbiome. Sci. Transl. Med. 6, 237r-265r. doi: 10.1126/scitranslmed.3008599

Abreu, M. T. (2010). Toll-like receptor signalling in the intestinal epithelium: how bacterial recognition shapes intestinal function. Nat. Rev. Immunol. 10, 131-144. doi: 10.1038/nri2707

Adams, J. B., Johansen, L. J., Powell, L. D., Quig, D., and Rubin, R. A. (2011). Gastrointestinal flora and gastrointestinal status in children with autismcomparisons to typical children and correlation with autism severity. BMC Gastroenterol. 11:22. doi: 10.1186/1471-230X-11-22

Ajslev, T. A., Andersen, C. S., Gamborg, M., Sorensen, T. I., and Jess, T. (2011). Childhood overweight after establishment of the gut microbiota: the role of delivery mode, pre-pregnancy weight and early administration of antibiotics. Int. J. Obes. (Lond). 35, 522-529. doi: 10.1038/ijo.2011.27

Al-Lahham, S. H., Peppelenbosch, M. P., Roelofsen, H., Vonk, R. J., and Venema, K. (2010). Biological effects of propionic acid in humans; metabolism, potential applications and underlying mechanisms. Biochim. Biophys. Acta 1801, 1175-1183. doi: 10.1016/j.bbalip.2010.07.007

Aroniadis, O. C., and Brandt, L. J. (2013). Fecal microbiota transplantation: past, present and future. Curr. Opin. Gastroenterol. 29, 79-84. doi: 10.1097/MOG.0b013e32835a4b3e

Ashwood, P., Krakowiak, P., Hertz-Picciotto, I., Hansen, R., Pessah, I., and Van de Water, J. (2011). Elevated plasma cytokines in autism spectrum disorders provide evidence of immune dysfunction and are associated with impaired behavioral outcome. Brain Behav. Immun. 25, 40-45. doi: 10.1016/j.bbi.2010.08.003

Atladóttir, H. Ó., Henriksen, T. B., Schendel, D. E., and Parner, E. T. (2012). Autism after infection, febrile episodes, and antibiotic use during pregnancy: an exploratory study. Pediatrics 130, e1447-e1454. doi: 10.1542/peds.2012-1107

Atladóttir, H. O., Thorsen, P., Østergaard, L., Schendel, D. E., Lemcke, S., Abdallah, M., et al. (2010). Maternal infection requiring hospitalization during pregnancy and autism spectrum disorders. J. Autism Dev. Disord. 40, 1423-1430. doi: 10.1007/s10803-010-1006-y

Azad, M. B., Konya, T., Maughan, H., Guttman, D. S., Field, C. J., Chari, R. S., et al. (2013). Gut microbiota of healthy Canadian infants: profiles by mode of delivery and infant diet at 4 months. CMAJ 185, 385-394. doi: 10.1503/cmaj.121189

Bandini, L. G., Anderson, S. E., Curtin, C., Cermak, S., Evans, E. W., Scampini, R., et al. (2010). Food selectivity in children with autism spectrum disorders and typically developing children. J. Pediatr. 157, 259-264. doi: 10.1016/j.jpeds.2010.02.013

Bienenstock, J., Kunze, W., and Forsythe, P. (2015). Microbiota and the gut-brain axis. Nutr. Rev. 73(Suppl. 1), 28-31. doi: 10.1093/nutrit/nuv019

Bokulich, N. A., Chung, J., Battaglia, T., Henderson, N., Jay, M., Li, H., et al. (2016). Antibiotics, birth mode, and diet shape microbiome maturation during early life. Sci. Transl. Med. 8, 343r-382r. doi: 10.1126/scitranslmed.aad7121

Borre, Y. E., O’Keeffe, G. W., Clarke, G., Stanton, C., Dinan, T. G., and Cryan, J. F. (2014). Microbiota and neurodevelopmental windows: implications for brain disorders. Trends Mol. Med. 20, 509-518. doi: 10.1016/j.molmed.2014. 05.002

\section{AUTHOR CONTRIBUTIONS}

All authors listed, have made substantial, direct and intellectual contribution to the work, and approved it for publication.

\section{ACKNOWLEDGMENTS}

This work was supported by grants from the National Natural Science Foundation of China (81200998) and the Beijing Natural Science Foundation (7092105 and 7112131).

Braniste, V., Al-Asmakh, M., Kowal, C., Anuar, F., Abbaspour, A., Tóth, M., et al. (2014). The gut microbiota influences blood-brain barrier permeability in mice. Sci. Transl. Med. 6, 158r-263r. doi: 10.1126/scitranslmed.3009759

Buescher, A. V., Cidav, Z., Knapp, M., and Mandell, D. S. (2014). Costs of autism spectrum disorders in the United Kingdom and the United States. JAMA Pediatr. 168, 721-728. doi: 10.1001/jamapediatrics.2014.210

Buffington, S. A., Di Prisco, G. V., Auchtung, T. A., Ajami, N. J., Petrosino, J. F., and Costa-Mattioli, M. (2016). Microbial reconstitution reverses maternal diet-induced social and synaptic deficits in offspring. Cell 165, 1762-1775. doi: 10.1016/j.cell.2016.06.001

Buie, T., Fuchs, G. R., Furuta, G. T. III, Kooros, K., Levy, J., Lewis, J. D., et al. (2010). Recommendations for evaluation and treatment of common gastrointestinal problems in children with ASDs. Pediatrics 125(Suppl. 1), S19-S29. doi: 10.1542/peds.2009-1878d

Burrus, C. J. (2012). A biochemical rationale for the interaction between gastrointestinal yeast and autism. Med. Hypotheses 79, 784-785. doi: 10.1016/j.mehy.2012.08.029

Castro, K., Baronio, D., Perry, I. S., Riesgo, R. D., and Gottfried, C. (2016). The effect of ketogenic diet in an animal model of autism induced by prenatal exposure to valproic acid. Nutr Neurosci. 8, 1-8. doi: 10.1080/1028415X.2015.1133029

Chaidez, V., Hansen, R. L., and Hertz-Picciotto, I. (2014). Gastrointestinal problems in children with autism, developmental delays or typical development. J. Autism Dev. Disord. 44, 1117-1127. doi: 10.1007/s10803-013-1973-x

Chambers, E. S., Viardot, A., Psichas, A., Morrison, D. J., Murphy, K. G., ZacVarghese, S. E., et al. (2015). Effects of targeted delivery of propionate to the human colon on appetite regulation, body weight maintenance and adiposity in overweight adults. Gut 64, 1744-1754. doi: 10.1136/gutjnl-2014-307913

Christensen, D. L., Baio, J., Van Naarden, B. K., Bilder, D., Charles, J., Constantino, J. N., et al. (2016). Prevalence and Characteristics of Autism Spectrum Disorder Among Children Aged 8 Years-Autism and Developmental Disabilities Monitoring Network, 11 Sites, United States, 2012. MMWR. Surveill. Summ. 65, 1-23. doi: 10.15585/mmwr.ss6503al

Chu, D. M., Antony, K. M., Ma, J., Prince, A. L., Showalter, L., Moller, M., et al. (2016). The early infant gut microbiome varies in association with a maternal high-fat diet. Genome Med. 8:77. doi: 10.1186/s13073-016-0330-z

Clarke, G., Grenham, S., Scully, P., Fitzgerald, P., Moloney, R. D., Shanahan, F., et al. (2013). The microbiome-gut-brain axis during early life regulates the hippocampal serotonergic system in a sex-dependent manner. Mol. Psychiatry 18, 666-673. doi: 10.1038/mp.2012.77

Cleophas, M. C., Crisan, T. O., Lemmers, H., Toenhake-Dijkstra, H., Fossati, G., Jansen, T. L., et al. (2016). Suppression of monosodium urate crystal-induced cytokine production by butyrate is mediated by the inhibition of class I histone deacetylases. Ann. Rheum. Dis. 75, 593-600. doi: 10.1136/annrheumdis-2014-206258

Connolly, N., Anixt, J., Manning, P., Ping-I Lin, D., Marsolo, K. A., and Bowers, K. (2016). Maternal metabolic risk factors for autism spectrum disorder-An analysis of electronic medical records and linked birth data. Autism Res. 9, 829-837. doi: 10.1002/aur.1586

Coury, D. L., Ashwood, P., Fasano, A., Fuchs, G., Geraghty, M., Kaul, A., et al. (2012). Gastrointestinal conditions in children with autism spectrum 
disorder: developing a research agenda. Pediatrics 130(Suppl. 2), S160-S168. doi: 10.1542/peds.2012-0900n

Critchfield, J. W., van Hemert, S., Ash, M., Mulder, L., and Ashwood, P. (2011). The potential role of probiotics in the management of childhood autism spectrum disorders. Gastroenterol. Res. Pract. 2011:161358. doi: 10.1155/2011/161358

Cryan, J. F., and Dinan, T. G. (2012). Mind-altering microorganisms: the impact of the gut microbiota on brain and behaviour. Nat. Rev. Neurosci. 13, 701-712. doi: $10.1038 / \mathrm{nrn} 3346$

Cryan, J. F., Harkin, A., Naughton, M., Kelly, J. P., and Leonard, B, E. (2000). Characterization of D-fenfluramine-induced hypothermia: evidence for multiple sites of action. Eur. J. Pharmacol. 390, 275-285. doi: 10.1016/S0014-2999(00)00012-1

Curran, E. A., O’Neill, S. M., Cryan, J. F., Kenny, L. C., Dinan, T. G., Khashan, A. S., et al. (2015). Research review: birth by caesarean section and development of autism spectrum disorder and attention-deficit/hyperactivity disorder: a systematic review and meta-analysis. J. Child Psychol. Psychiatry 56, 500-508. doi: $10.1111 /$ jcpp. 12351

De Angelis, M., Francavilla, R., Piccolo, M., De Giacomo, A., and Gobbetti, M. (2015). Autism spectrum disorders and intestinal microbiota. Gut Microbes 6, 207-213. doi: 10.1080/19490976.2015.1035855

De Angelis, M., Piccolo, M., Vannini, L., Siragusa, S., De Giacomo, A., Serrazzanetti, D. I., et al. (2013). Fecal microbiota and metabolome of children with autism and pervasive developmental disorder not otherwise specified. PLoS ONE 8:e76993. doi: 10.1371/journal.pone.0076993

DeCastro, M., Nankova, B. B., Shah, P., Patel, P., Mally, P. V., Mishra, R., et al. (2005). Short chain fatty acids regulate tyrosine hydroxylase gene expression through a cAMP-dependent signaling pathway. Brain Res. Mol. Brain Res. 142, 28-38. doi: 10.1016/j.molbrainres.2005.09.002

de Magistris, L., Familiari, V., Pascotto, A., Sapone, A., Frolli, A., Iardino, P., et al. (2010). Alterations of the intestinal barrier in patients with autism spectrum disorders and in their first-degree relatives. J. Pediatr. Gastroenterol. Nutr. 51, 418-424. doi: 10.1097/MPG.0b013e3181dcc4a5

de Theije, C. G., Wopereis, H., Ramadan, M., van Eijndthoven, T., Lambert, J., Knol, J., et al. (2014a). Altered gut microbiota and activity in a murine model of autism spectrum disorders. Brain Behav. Immun. 37, 197-206. doi: 10.1016/j.bbi.2013.12.005

de Theije, C. G., Wu, J., da Silva, S. L., Kamphuis, P. J., Garssen, J., Korte, S. M., et al. (2011). Pathways underlying the gut-to-brain connection in autism spectrum disorders as future targets for disease management. Eur. J. Pharmacol. 668(Suppl. 1), S70-S80. doi: 10.1016/j.ejphar.2011.07.013

de Theije, C. G., Wu, J., Koelink, P. J., Korte-Bouws, G. A., Borre, Y., Kas, M. J., et al. (2014b). Autistic-like behavioural and neurochemical changes in a mouse model of food allergy. Behav. Brain Res. 261, 265-274. doi: 10.1016/j.bbr.2013.12.008

De Vadder, F., Kovatcheva-Datchary, P., Goncalves, D., Vinera, J., Zitoun, C., Duchampt, A., et al. (2014). Microbiota-generated metabolites promote metabolic benefits via gut-brain neural circuits. Cell 156, 84-96. doi: 10.1016/j.cell.2013.12.016

Diamond, B., Huerta, P. T., Tracey, K., and Volpe, B. T. (2011). It takes guts to grow a brain: increasing evidence of the important role of the intestinal microflora in neuro- and immune-modulatory functions during development and adulthood. Bioessays 33, 588-591. doi: 10.1002/bies.201100042

Diaz Heijtz, R., Wang, S., Anuar, F., Qian, Y., Björkholm, B., Samuelsson, A., et al. (2011). Normal gut microbiota modulates brain development and behavior. Proc. Natl. Acad. Sci. U.S.A. 108, 3047-3052. doi: 10.1073/pnas.1010529108

Dicksved, J., Schreiber, O., Willing, B., Petersson, J., Rang, S., Phillipson, M., et al. (2012). Lactobacillus reuteri maintains a functional mucosal barrier during DSS treatment despite mucus layer dysfunction. PLoS ONE 7:e46399. doi: 10.1371 /journal.pone.0046399

DiGiulio, D. B., Romero, R., Amogan, H. P., Kusanovic, J. P., Bik, E. M., Gotsch, F., et al. (2008). Microbial prevalence, diversity and abundance in amniotic fluid during preterm labor: a molecular and culture-based investigation. PLOS ONE 3:e3056. doi: 10.1371/journal.pone.0003056

Dominguez-Bello, M. G., Costello, E. K., Contreras, M., Magris, M., Hidalgo, G., Fierer, N., et al. (2010). Delivery mode shapes the acquisition and structure of the initial microbiota across multiple body habitats in newborns. Proc. Natl. Acad. Sci. U.S.A. 107, 11971-11975. doi: 10.1073/pnas.1002601107
Duncan, S. H., Belenguer, A., Holtrop, G., Johnstone, A. M., Flint, H. J., and Lobley, G. E. (2007). Reduced dietary intake of carbohydrates by obese subjects results in decreased concentrations of butyrate and butyrate-producing bacteria in feces. Appl. Environ. Microbiol. 73, 1073-1078. doi: 10.1128/AEM. 02340-06

Eisenstein, M. (2016). Microbiome: bacterial broadband. Nature 533, S104-S106. doi: 10.1038/533S104a

Emanuele, E., Orsi, P., Boso, M., Broglia, D., Brondino, N., Barale, F., et al. (2010). Low-grade endotoxemia in patients with severe autism. Neurosci. Lett. 471, 162-165. doi: $10.1016 /$ j.neulet.2010.01.033

Fakhoury, M. (2015). Autistic spectrum disorders: a review of clinical features, theories and diagnosis. Int. J. Dev. Neurosci. 43, 70-77. doi: 10.1016/j.ijdevneu.2015.04.003

Finegold, S. M. (2011). Desulfovibrio species are potentially important in regressive autism. Med. Hhypotheses 77, 270-274. doi: 10.1016/j.mehy.2011.04.032

Finegold, S. M., Dowd, S. E., Gontcharova, V., Liu, C., Henley, K. E., Wolcott, R. D., et al. (2010). Pyrosequencing study of fecal microflora of autistic and control children. Anaerobe 16, 444-453. doi: 10.1016/j.anaerobe.2010.06.008

Finegold, S. M., Molitoris, D., Song, Y., Liu, C., Vaisanen, M. L., Bolte, E., et al. (2002). Gastrointestinal microflora studies in late-onset autism. Clin. Infect. Dis. 35, S6-S16. doi: 10.1086/341914

Fiorentino, M., Sapone, A., Senger, S., Camhi, S. S., Kadzielski, S. M., Buie, T. M., et al. (2016). Blood-brain barrier and intestinal epithelial barrier alterations in autism spectrum disorders. Mol. Autism. 7:49. doi: 10.1186/s13229-016-0110-z

Forsythe, P., Bienenstock, J., and Kunze, W. A. (2014). Vagal pathways for microbiome-brain-gut axis communication. Adv. Exp. Med. Biol. 817, 115-133. doi: 10.1007/978-1-4939-0897-4_5

Geier, D. A., Kern, J. K., Davis, G., King, P. G., Adams, J. B., Young, J. L., et al. (2011). A prospective double-blind, randomized clinical trial of levocarnitine to treat autism spectrum disorders. Med. Sci. Monit. 17, I15-I23. doi: 10.12659/MSM.881792

Gorrindo, P., Williams, K. C., Lee, E. B., Walker, L. S., McGrew, S. G., and Levitt, P. (2012). Gastrointestinal dysfunction in autism: parental report, clinical evaluation, and associated factors. Autism Res. 5, 101-108. doi: 10.1002/aur.237

Grenham, S., Clarke, G., Cryan, J. F., and Dinan, T. G. (2011). Braingut-microbe communication in health and disease. Front. Physiol. 2:94. doi: 10.3389/fphys.2011.00094

Grimaldi, R., Cela, D., Swann, J. R., Vulevic, J., Gibson, G. R., Tzortzis, G., et al. (2017). In vitro fermentation of B-GOS: impact on faecal bacterial populations and metabolic activity in autistic and non-autistic children. FEMS Microbiol. Ecol. 93:fiw233. doi: 10.1093/femsec/fiw233

Grossi, E., Melli, S., Dunca, D., and Terruzzi, V. (2016). Unexpected improvement in core autism spectrum disorder symptoms after long-term treatment with probiotics. SAGE Open Med. Case Rep. 4:2050313X16666231. doi: $10.1177 / 2050313 X 16666231$

Hallmayer, J., Cleveland, S., Torres, A., Phillips, J., Cohen, B., Torigoe, T., et al. (2011). Genetic heritability and shared environmental factors among twin pairs with autism. Arch. Gen. Psychiatry 68, 1095-1102. doi: 10.1001/archgenpsychiatry.2011.76

Hanley, H. G., Stahl, S. M., and Freedman, D. X. (1977). Hyperserotonemia and amine metabolites in autistic and retarded children. Arch. Gen. Psychiatry 34, 521-531. doi: 10.1001/archpsyc.1977.01770170031002

Hoban, A. E., Moloney, R. D., Golubeva, A. V., McVey Neufeld, K. A., O’Sullivan, O., Patterson, E., et al. (2016). Behavioural and neurochemical consequences of chronic gut microbiota depletion during adulthood in the rat. Neuroscience 339, 463-477. doi: 10.1016/j.neuroscience.2016.10.003

Hsiao, E. Y., McBride, S. W., Hsien, S., Sharon, G., Hyde, E. R., McCue, T., et al. (2013). Microbiota modulate behavioral and physiological abnormalities associated with neurodevelopmental disorders. Cell 155, 1451-1463. doi: $10.1016 /$ j.cell.2013.11.024

Iovene, M. R., Bombace, F., Maresca, R., Sapone, A., Iardino, P., Picardi, A., et al. (2017). Intestinal jimenez dysbiosis and yeast isolation in stool of subjects with autism spectrum disorders. Mycopathologia 182, 349-363. doi: 10.1007/s11046-016-0068-6

Jimenéz, E., Marìn, M. L., Martín, R., Odriozola, J. M., Olivares, M., Xaus, J., et al. (2008). Is meconium from healthy newborns actually sterile? Res. Microbiol. 159, 187-193. doi: 10.1016/j.resmic.2007.12.007 
Joossens, M., Huys, G., Cnockaert, M., De Preter, V., Verbeke, K., Rutgeerts, P., et al. (2011). Dysbiosis of the faecal microbiota in patients with Crohn's disease and their unaffected relatives. Gut 60, 631-637. doi: 10.1136/gut.2010.223263

Jostins, L., Ripke, S., Weersma, R. K., Duerr, R. H., McGovern, D. P., Hui, K. Y., et al. (2012). Host-microbe interactions have shaped the genetic architecture of inflammatory bowel disease. Nature 491, 119-124. doi: 10.1038/nature11582

Kaluzna-Czaplinska, J., and Blaszczyk, S. (2012). The level of arabinitol in autistic children after probiotic therapy. Nutrition 28, 124-126. doi: 10.1016/j.nut.2011.08.002

Kang, D. W., Adams, J. B., Gregory, A. C., Borody, T., Chittick, L., Fasano, A., et al. (2017). Microbiota Transfer Therapy alters gut ecosystem and improves gastrointestinal and autism symptoms: an open-label study. Microbiome 5:10. doi: 10.1186/s40168-016-0225-7

Kang, D. W., Park, J. G., Ilhan, Z. E., Wallstrom, G., Labaer, J., Adams, J. B., et al. (2013). Reduced incidence of Prevotella and other fermenters in intestinal microflora of autistic children. PLoS ONE 8:e68322. doi: 10.1371/journal.pone.0068322

Kantarcioglu, A. S., Kiraz, N., and Aydin, A. (2016). Microbiota-gut-brain axis: yeast species isolated from stool samples of children with suspected or diagnosed autism spectrum disorders and in vitro susceptibility against nystatin and fluconazole. Mycopathologia 181, 1-7. doi: 10.1007/s11046-0159949-3

Karczewski, J., Troost, F. J., Konings, I., Dekker, J., Kleerebezem, M., Brummer, R. J., et al. (2010). Regulation of human epithelial tight junction proteins by Lactobacillus plantarum in vivo and protective effects on the epithelial barrier. Am. J. Physiol. Gastrointest. Liver Physiol. 298, G851-G859. doi: 10.1152/ajpgi.00327.2009

Kelly, C. R., Kahn, S., Kashyap, P., Laine, L., Rubin, D., Atreja, A., et al. (2015). Update on fecal microbiota transplantation 2015: indications, methodologies, mechanisms, and outlook. Gastroenterology 149, 223-237. doi: 10.1053/j.gastro.2015.05.008

Knivsberg, A. M., Reichelt, K. L., Høien, T., and Nodland, M. (2002). A randomised, controlled study of dietary intervention in autistic syndromes. Nutr. Neurosci. 5, 251-261. doi: 10.1080/10284150290028945

Koenig, J. E., Spor, A., Scalfone, N., Fricker, A. D., Stombaugh, J., Knight, R., et al. (2011). Succession of microbial consortia in the developing infant gut microbiome. Proc. Natl. Acad. Sci. U.S.A. 108(Suppl. 1), 4578-4585. doi: 10.1073/pnas.1000081107

Konsman, J. P., Luheshi, G. N., Bluthe, R. M., and Dantzer, R. (2000). The vagus nerve mediates behavioural depression, but not fever, in response to peripheral immune signals; a functional anatomical analysis. Eur. J. Neurosci. 12, 4434-4446. doi: 10.1046/j.0953-816X.2000.01319.x

Kushak, R. I., Buie, T. M., Murray, K. F., Newburg, D. S., Chen, C., Nestoridi, E., et al. (2016). Evaluation of intestinal function in children with autism and gastrointestinal symptoms. J. Pediatr. Gastroenterol. Nutr. 62, 687-691. doi: 10.1097/MPG.0000000000001174

Lessa, F. C., Mu, Y., Bamberg, W. M., Beldavs, Z. G., Dumyati, G. K., Dunn, J. R., et al. (2015). Burden of Clostridium difficile infection in the United States. $N$. Engl. J. Med. 372, 825-834. doi: 10.1056/NEJMoa1408913

Li, J., Jia, H., Cai, X., Zhong, H., Feng, Q., Sunagawa, S., et al. (2014). An integrated catalog of reference genes in the human gut microbiome. Nat. Biotechnol. 32, 834-841. doi: 10.1038/nbt.2942

Li, W., Dowd, S. E., Scurlock, B., Acosta-Martinez, V., and Lyte, M. (2009a). Memory and learning behavior in mice is temporally associated with diet-induced alterations in gut bacteria. Physiol. Behav. 96, 557-567. doi: 10.1016/j.physbeh.2008.12.004

Li, X., Chauhan, A., Sheikh, A. M., Patil, S., Chauhan, V., Li, X. M., et al. (2009b). Elevated immune response in the brain of autistic patients. J. Neuroimmunol. 207, 111-116. doi: 10.1016/j.jneuroim.2008.12.002

Ma, J., Prince, A. L., Bader, D., Hu, M., Ganu, R., Baquero, K., et al. (2014). High-fat maternal diet during pregnancy persistently alters the offspring microbiome in a primate model. Nat. Commun. 5:3889. doi: 10.1038/ncomms4889

Macfabe, D. F. (2012). Short-chain fatty acid fermentation products of the gut microbiome: implications in autism spectrum disorders. Microb. Ecol. Health Dis. 23, 1-24. doi: 10.3402/mehd.v23i0.19260

MacFabe, D. F., Cain, D. P., Rodriguez-Capote, K., Franklin, A. E., Hoffman, J. E., Boon, F., et al. (2007). Neurobiological effects of intraventricular propionic acid in rats: possible role of short chain fatty acids on the pathogenesis and characteristics of autism spectrum disorders. Behav. Brain Res. 176, 149-169. doi: 10.1016/j.bbr.2006.07.025

MacFabe, D. F., Cain, N. E., Boon, F., Ossenkopp, K. P., and Cain, D. P. (2011). Effects of the enteric bacterial metabolic product propionic acid on object-directed behavior, social behavior, cognition, and neuroinflammation in adolescent rats: relevance to autism spectrum disorder. Behav. Brain Res. 217, 47-54. doi: 10.1016/j.bbr.2010.10.005

Malhi, P., Venkatesh, L., Bharti, B., and Singhi, P. (2017). Feeding problems and nutrient intake in children with and without autism: a comparative study. Indian J. Pediatr. 84, 283-288. doi: 10.1007/s12098-016-2285-x

Mankad, D., Dupuis, A., Smile, S., Roberts, W., Brian, J., Lui, T., et al. (2015). A randomized, placebo controlled trial of omega- 3 fatty acids in the treatment of young children with autism. Mol. Autism 6:18. doi: 10.1186/s13229-015-0010-7

Mariadason, J. M., Corner, G. A., and Augenlicht, L. H. (2000). Genetic reprogramming in pathways of colonic cell maturation induced by short chain fatty acids: comparison with trichostatin A, sulindac, and curcumin and implications for chemoprevention of colon cancer. Cancer Res. 60, 4561-4572.

Marler, S., Ferguson, B. J., Lee, E. B., Peters, B., Williams, K. C., McDonnell, E., et al. (2016). Brief report: whole blood serotonin levels and gastrointestinal symptoms in autism spectrum disorder. J. Autism Dev. Disord. 46, 1124-1130. doi: 10.1007/s10803-015-2646-8

Martin, R., Makino, H., Cetinyurek, Y. A., Ben-Amor, K., Roelofs, M., Ishikawa, E., et al. (2016). Early-life events, including mode of delivery and type of feeding, siblings and gender, shape the developing gut microbiota. PLoS ONE 11:e158498. doi: 10.1371/journal.pone.0158498

Mayer, E. A. (2011). Gut feelings: the emerging biology of gut-brain communication. Nat. Rev. Neurosci. 12, 453-466. doi: 10.1038/nrn3071

Mayer, E. A., Tillisch, K., and Gupta, A. (2015). Gut/brain axis and the microbiota. J. Clin. Invest. 125, 926-938. doi: 10.1172/JCI76304

McElhanon, B. O., McCracken, C., Karpen, S., and Sharp, W. G. (2014). Gastrointestinal symptoms in autism spectrum disorder: a meta-analysis. Pediatrics 133, 872-883. doi: 10.1542/peds.2013-3995

Mead, J., and Ashwood, P. (2015). Evidence supporting an altered immune response in ASD. Immunol. Lett. 163, 49-55. doi: 10.1016/j.imlet.2014.11.006

Messaoudi, M., Lalonde, R., Violle, N., Javelot, H., Desor, D., Nejdi, A., et al. (2011). Assessment of psychotropic-like properties of a probiotic formulation (Lactobacillus helveticus R0052 and Bifidobacterium longum R0175) in rats and human subjects. Br. J. Nutr. 105, 755-764. doi: 10.1017/S00071145100 04319

Millward, C., Ferriter, M., Calver, S., and Connell-Jones, G. (2004). Gluten- and casein-free diets for autistic spectrum disorder. Cochrane Database Syst. Rev. D3498. doi: 10.1002/14651858.CD003498.pub2

Ming, X., Stein, T. P., Barnes, V., Rhodes, N., and Guo, L. (2012). Metabolic perturbance in autism spectrum disorders: a metabolomics study. J. Proteome Res. 11, 5856-5862. doi: 10.1021/pr300910n

Mitsui, R., Ono, S., Karaki, S., and Kuwahara, A. (2005). Neural and nonneural mediation of propionate-induced contractile responses in the rat distal colon. Neurogastroenterol. Motil. 17, 585-594. doi: 10.1111/j.1365-2982.2005. 00669.x

Mulder, E. J., Anderson, G. M., Kema, I. P., de Bildt, A., van Lang, N. D., den Boer, J. A., et al. (2004). Platelet serotonin levels in pervasive developmental disorders and mental retardation: diagnostic group differences, within-group distribution, and behavioral correlates. J. Am. Acad. Child Adolesc. Psychiatry 43, 491-499. doi: 10.1097/00004583-200404000-00016

Neufeld, K. M., Kang, N., Bienenstock, J., and Foster, J. A. (2011). Reduced anxiety-like behavior and central neurochemical change in germ-free mice. Neurogastroenterol. Motil. 23, 255-264, e119. doi: 10.1111/j.1365-2982.2010.01620.x

Newell, C., Bomhof, M. R., Reimer, R. A., Hittel, D. S., Rho, J. M., and Shearer, J. (2016). Ketogenic diet modifies the gut microbiota in a murine model of autism spectrum disorder. Mol. Autism 7:37. doi: 10.1186/s13229-016-0099-3

Niehus, R., and Lord, C. (2006). Early medical history of children with autism spectrum disorders. J. Dev. Behav. Pediatr. 27, S120-S127. doi: 10.1097/00004703-200604002-00010

Noto, A., Fanos, V., Barberini, L., Grapov, D., Fattuoni, C., Zaffanello, M., et al. (2014). The urinary metabolomics profile of an Italian autistic children population and their unaffected siblings. J. Matern. Fetal Neonatal Med. 27(Suppl. 2), 46-52. doi: 10.3109/14767058.2014.954784 
O’Mahony, L., McCarthy, J., Kelly, P., Hurley, G., Luo, F., Chen, K., et al. (2005). Lactobacillus and bifidobacterium in irritable bowel syndrome: symptom responses and relationship to cytokine profiles. Gastroenterology 128, 541-551. doi: 10.1053/j.gastro.2004.11.050

Onore, C., Careaga, M., and Ashwood, P. (2012). The role of immune dysfunction in the pathophysiology of autism. Brain Behav. Immun. 26, 383-392. doi: 10.1016/j.bbi.2011.08.007

Ooi, Y. P., Weng, S. J., Jang, L. Y., Low, L., Seah, J., Teo, S., et al. (2015). Omega-3 fatty acids in the management of autism spectrum disorders: findings from an open-label pilot study in Singapore. Eur. J. Clin. Nutr. 69, 969-971. doi: 10.1038/ejcn.2015.28

Ossenkopp, K. P., Foley, K. A., Gibson, J., Fudge, M. A., Kavaliers, M., Cain, D. P., et al. (2012). Systemic treatment with the enteric bacterial fermentation product, propionic acid, produces both conditioned taste avoidance and conditioned place avoidance in rats. Behav. Brain Res. 227, 134-141. doi: 10.1016/j.bbr.2011.10.045

Pare, C. M., Sandler, M., and Stacey, R. S. (1960). 5-Hydroxyindoles in mental deficiency. J. Neurol. Neurosurg. Psychiatr. 23, 341-346. doi: 10.1136/jnnp.23.4.341

Parracho, H. M., Bingham, M. O., Gibson, G. R., and McCartney, A. L. (2005). Differences between the gut microflora of children with autistic spectrum disorders and that of healthy children. J. Med. Microbiol. 54, 987-991. doi: $10.1099 /$ jmm.0.46101-0

Patel, R. M., Myers, L. S., Kurundkar, A. R., Maheshwari, A., Nusrat, A., and Lin, P. W. (2012). Probiotic bacteria induce maturation of intestinal claudin 3 expression and barrier function. Am. J. Pathol. 180, 626-635. doi: 10.1016/j.ajpath.2011.10.025

Penn, A. H., Carver, L. J., Herbert, C. A., Lai, T. S., McIntire, M. J., Howard, J. T., et al. (2016). Breast milk protects against gastrointestinal symptoms in infants at high risk for autism during early development. J. Pediatr. Gastroenterol. Nutr. 62, 317-327. doi: 10.1097/MPG.0000000000000907

Pennesi, C. M., and Klein, L. C. (2012). Effectiveness of the gluten-free, caseinfree diet for children diagnosed with autism spectrum disorder: based on parental report. Nutr. Neurosci. 15, 85-91. doi: 10.1179/1476830512Y.00000 00003

Persico, A. M., and Napolioni, V. (2013). Urinary p-cresol in autism spectrum disorder. Neurotoxicol. Tertol. 36, 82-90. doi: 10.1016/j.ntt.2012.09.002

Quigley, E. M. (2016). Leaky gut-concept or clinical entity? Curr. Opin. Gastroenterol. 32, 74-79. doi: 10.1097/MOG.0000000000000243

Rao, A. V., Bested, A. C., Beaulne, T. M., Katzman, M. A., Iorio, C., Berardi, J. M., et al. (2009). A randomized, double-blind, placebo-controlled pilot study of a probiotic in emotional symptoms of chronic fatigue syndrome. Gut Pathog. 1, 6. doi: 10.1186/1757-4749-1-6

Rosenfeld, C. S. (2015). Microbiome disturbances and autism spectrum disorders. Drug Metab. Dispos. 43, 1557-1571. doi: 10.1124/dmd.115.063826

Rossen, N. G., MacDonald, J. K., de Vries, E. M., D’Haens, G. R., de Vos, W. M., Zoetendal, E. G., et al. (2015). Fecal microbiota transplantation as novel therapy in gastroenterology: a systematic review. World J. Gastroenterol. 21, 5359-5371. doi: 10.3748/wjg.v21.i17.5359

Rossignol, D. A., and Frye, R. E. (2012). A review of research trends in physiological abnormalities in autism spectrum disorders: immune dysregulation, inflammation, oxidative stress, mitochondrial dysfunction and environmental toxicant exposures. Mol. Psychiatry 17, 389-401. doi: 10.1038/mp.2011.165

Ruskin, D. N., Svedova, J., Cote, J. L., Sandau, U., Rho, J. M., Kawamura, M. J. Jr, et al. (2013). Ketogenic diet improves core symptoms of autism in BTBR mice. PLoS ONE 8:e65021. doi: 10.1371/journal.pone.0065021

Sandin, S., Lichtenstein, P., Kuja-Halkola, R., Larsson, H., Hultman, C. M., and Reichenberg, A. (2014). The familial risk of autism. JAMA 311, 1770-1777. doi: $10.1001 /$ jama.2014.4144

Sandler, R. H., Finegold, S. M., Bolte, E. R., Buchanan, C. P., Maxwell, A. P., Väisänen, M. L., et al. (2000). Short-term benefit from oral vancomycin treatment of regressive-onset autism. J. Child Neurol. 15, 429-435. doi: $10.1177 / 088307380001500701$

Santocchi, E., Guiducci, L., Fulceri, F., Billeci, L., Buzzigoli, E., Apicella, F., et al. (2016). Gut to brain interaction in Autism Spectrum Disorders: a randomized controlled trial on the role of probiotics on clinical, biochemical and neurophysiological parameters. BMC Psychiatry. 16:183. doi: $10.1186 / \mathrm{s} 12888-016-0887-5$
Schain, R. J., and Freedman, D. X. (1961). Studies on 5-hydroxyindole metabolism in autistic and other mentally retarded children. J. Pediatr. 58, 315-320. doi: 10.1016/S0022-3476(61)80261-8

Schreck, K. A., and Williams, K. (2006). Food preferences and factors influencing food selectivity for children with autism spectrum disorders. Res. Dev. Disabil. 27, 353-363. doi: 10.1016/j.ridd.2005.03.005

Schreck, K. A., Williams, K., and Smith, A. F. (2004). A comparison of eating behaviors between children with and without autism. J. Autism Dev. Disord. 34, 433-438. doi: 10.1023/B:JADD.0000037419.78531.86

Schultz, S. T., Klonoff-Cohen, H. S., Wingard, D. L., Akshoomoff, N. A., Macera, C. A., Ji, M., et al. (2006). Breastfeeding, infant formula supplementation, and autistic disorder: the results of a parent survey. Int. Breastfeed. J. 1:16. doi: 10.1186/1746-4358-1-16

Sharma, M., and Shukla, G. (2016). Metabiotics: one step ahead of probiotics; an insight into mechanisms involved in anticancerous effect in colorectal cancer. Front. Microbiol 7:1940. doi: 10.3389/fmicb.2016.01940

Sharp, W. G., Berry, R. C., McCracken, C., Nuhu, N. N., Marvel, E., Saulnier, C. A., et al. (2013). Feeding problems and nutrient intake in children with autism spectrum disorders: a meta-analysis and comprehensive review of the literature. J. Autism Dev. Disord. 43, 2159-2173. doi: 10.1007/s10803-013-1771-5

Shaw, W. (2010). Increased urinary excretion of a 3-(3-hydroxyphenyl)-3hydroxypropionic acid (HPHPA), an abnormal phenylalanine metabolite of Clostridia spp. in the gastrointestinal tract, in urine samples from patients with autism and schizophrenia. Nutr. Neurosci. 13, 135-143. doi: 10.1179/147683010X12611460763968

Sheldon, A. L., and Robinson, M. B. (2007). The role of glutamate transporters in neurodegenerative diseases and potential opportunities for intervention. Neurochem. Int. 51, 333-355. doi: 10.1016/j.neuint.2007.03.012

Shimmura, C., Suda, S., Tsuchiya, K. J., Hashimoto, K., Ohno, K., Matsuzaki, H., et al. (2011). Alteration of plasma glutamate and glutamine levels in children with high-functioning autism. PLoS ONE 6:e25340. doi: 10.1371 /journal.pone.0025340

Shultz, S. R., MacFabe, D. F., Ossenkopp, K. P., Scratch, S., Whelan, J., Taylor, R., et al. (2008). Intracerebroventricular injection of propionic acid, an enteric bacterial metabolic end-product, impairs social behavior in the rat: implications for an animal model of autism. Neuropharmacology 54, 901-911. doi: 10.1016/j.neuropharm.2008.01.013

Son, J. S., Zheng, L. J., Rowehl, L. M., Tian, X., Zhang, Y., Zhu, W., et al. (2015). Comparison of fecal microbiota in children with autism spectrum disorders and neurotypical siblings in the simons simplex collection. PLoS ONE 10:e137725. doi: 10.1371/journal.pone.0137725

Spiller, R., and Major, G. (2016). IBS and IBD - separate entities or on a spectrum? Nat. Rev. Gastroenterol. Hepatol. 13, 613-621. doi: 10.1038/nrgastro.2016.141

Strati, F., Cavalieri, D., Albanese, D., De Felice, C., Donati, C., Hayek, J., et al. (2017). New evidences on the altered gut microbiota in autism spectrum disorders. Microbiome 5:24. doi: 10.1186/s40168-017-0242-1

Tamburini, S., Shen, N., Wu, H. C., and Clemente, J. C. (2016). The microbiome in early life: implications for health outcomes. Nat. Med. 22, 713-722. doi: $10.1038 / \mathrm{nm} .4142$

Thomas, R. H., Meeking, M. M., Mepham, J. R., Tichenoff, L., Possmayer, F., Liu, S., et al. (2012). The enteric bacterial metabolite propionic acid alters brain and plasma phospholipid molecular species: further development of a rodent model of autism spectrum disorders. J. Neuroinflammation. 9:153. doi: 10.1186/1742-2094-9-153

Tillisch, K., Labus, J., Kilpatrick, L., Jiang, Z., Stains, J., Ebrat, B., et al. (2013). Consumption of fermented milk product with probiotic modulates brain activity. Gastroenterology 144, 1394-1401, 1401. doi: 10.1053/j.gastro.2013.02.043

Tomova, A., Husarova, V., Lakatosova, S., Bakos, J., Vlkova, B., Babinska, K., et al. (2015). Gastrointestinal microbiota in children with autism in Slovakia. Physiol. Behav. 138, 179-187. doi: 10.1016/j.physbeh.2014.10.033

Tremaroli, V., and Bäckhed, F. (2012). Functional interactions between the gut microbiota and host metabolism. Nature 489, 242-249. doi: 10.1038/nature11552

Ulluwishewa, D., Anderson, R. C., McNabb, W. C., Moughan, P. J., Wells, J. M., and Roy, N. C. (2011). Regulation of tight junction permeability by intestinal bacteria and dietary components. J. Nutr. 141, 769-776. doi: $10.3945 /$ jn. 110.135657 
Valsecchi, C., Carlotta, T. S., and Castellazzi, A. (2016). Gut microbiota and obesity. J. Clin. Gastroenterol. 50(Suppl. 2), 13-15, 2015, S157-S158. doi: 10.1097/MCG.0000000000000715

Veenstra-VanderWeele, J., Muller, C. L., Iwamoto, H., Sauer, J. E., Owens, W. A., Shah, C. R., et al. (2012). Autism gene variant causes hyperserotonemia, serotonin receptor hypersensitivity, social impairment and repetitive behavior. Proc. Natl. Acad. Sci. U.S.A. 109, 5469-5474. doi: 10.1073/pnas.1112345109

Verma, A., and Shukla, G. (2014). Synbiotic (Lactobacillus rhamnosus+Lactobacillus acidophilus+inulin) attenuates oxidative stress and colonic damage in 1, 2 dimethylhydrazine dihydrochloride-induced colon carcinogenesis in Sprague-Dawley rats: a long-term study. Eur. J. Cancer Prev. 23, 550-559. doi: 10.1097/CEJ.0000000000000054

Verna, E. C., and Lucak, S. (2010). Use of probiotics in gastrointestinal disorders: what to recommend? Therap. Adv. Gastroenterol. 3, 307-319. doi: 10.1177/1756283X10373814

Vrieze, A., de Groot, P. F., Kootte, R. S., Knaapen, M., van Nood, E., and Nieuwdorp, M. (2013). Fecal transplant: a safe and sustainable clinical therapy for restoring intestinal microbial balance in human disease? Best Pract. Res. Clin. Gastroenterol. 27, 127-137. doi: 10.1016/j.bpg.2013.03.003

Wang, L., Christophersen, C. T., Sorich, M. J., Gerber, J. P., Angley, M. T., and Conlon, M. A. (2012). Elevated fecal short chain fatty acid and ammonia concentrations in children with autism spectrum disorder. Dig. Dis. Sci. 57, 2096-2102. doi: 10.1007/s10620-012-2167-7

Wang, L., Christophersen, C. T., Sorich, M. J., Gerber, J. P., Angley, M. T., and Conlon, M. A. (2013). Increased abundance of Sutterella spp. and Ruminococcus torques in feces of children with autism spectrum disorder. Mol. Autism 4:42. doi: 10.1186/2040-2392-4-42

Wang, L. W., Tancredi, D. J., and Thomas, D. W. (2011). The prevalence of gastrointestinal problems in children across the United States with autism spectrum disorders from families with multiple affected members. J. Dev. Behav. Pediatr. 32, 351-360. doi: 10.1097/DBP.0b013e318 21bd06a

West, R., Roberts, E., Sichel, L. S., and Sichel, J. (2013). Improvements in gastrointestinal symptoms among children with autism spectrum disorder receiving the Delpro ${ }^{\circledR}$ probiotic and immunomodulatory formulation. J. Probiotics Health. 1:2. doi: 10.4172/2329-8901.1000102
Whorwell, P. J., Altringer, L., Morel, J., Bond, Y., Charbonneau, D., O’Mahony, L., et al. (2006). Efficacy of an encapsulated probiotic Bifidobacterium infantis 35624 in women with irritable bowel syndrome. Am. J. Gastroenterol. 101, 1581-1590. doi: 10.1111/j.1572-0241.2006.00734.x

Wu, G. D., Chen, J., Hoffmann, C., Bittinger, K., Chen, Y. Y., Keilbaugh, S. A., et al. (2011). Linking long-term dietary patterns with gut microbial enterotypes. Science 334, 105-108. doi: 10.1126/science.1208344

Yarandi, S. S., Peterson, D. A., Treisman, G. J., Moran, T. H., and Pasricha, P. J. (2016). Modulatory effects of gut microbiota on the central nervous system: how gut could play a role in neuropsychiatric health and diseases. $J$. Neurogastroenterol. Motil. 22, 201-212. doi: 10.5056/jnm15146

Yassour, M., Vatanen, T., Siljander, H., Hämäläinen, A. M., Härkönen, T., Ryhänen, S. J., et al. (2016). Natural history of the infant gut microbiome and impact of antibiotic treatment on bacterial strain diversity and stability. Sci. Transl. Med. 8, 343r-381r. doi: 10.1126/scitranslmed.aad0917

Yatsunenko, T., Rey, F. E., Manary, M. J., Trehan, I., Dominguez-Bello, M. G., Contreras, M., et al. (2012). Human gut microbiome viewed across age and geography. Nature 486, 222-227. doi: 10.1038/nature11053

Zelante, T., Iannitti, R. G., Cunha, C., De Luca, A., Giovannini, G., Pieraccini, G., et al. (2013). Tryptophan catabolites from microbiota engage aryl hydrocarbon receptor and balance mucosal reactivity via interleukin-22. Immunity 39, 372-385. doi: 10.1016/j.immuni.2013.08.003

Zhang, F., Luo, W., Shi, Y., Fan, Z., and Ji, G. (2012). Should we standardize the 1,700-year-old fecal microbiota transplantation? Am. J. Gastroenterol. 107 1755-1756. doi: 10.1038/ajg.2012.251

Conflict of Interest Statement: The authors declare that the research was conducted in the absence of any commercial or financial relationships that could be construed as a potential conflict of interest.

Copyright (c) $2017 \mathrm{Li}$, Han, Dy and Hagerman. This is an open-access article distributed under the terms of the Creative Commons Attribution License (CC BY). The use, distribution or reproduction in other forums is permitted, provided the original author(s) or licensor are credited and that the original publication in this journal is cited, in accordance with accepted academic practice. No use, distribution or reproduction is permitted which does not comply with these terms. 